\title{
Possible Influences on Ammonia Nitrogen Determination by Nessler's Reagent Spectrophotometry
}

\author{
Cheng-yuan Hu, Qin-yi Gu, Hao Guo, Ying-li Yao, Can-xu Yao, Jing-ping Wang*, Jian Chen* \\ School of Chemical and Environmental Engineering,Yancheng Teachers University, \\ Jangsu, 224007, China
}

The research is supported by a Project Funded by the brand professional project form Yancheng teachers college (2016) and the teaching reform and practice of medicinal chemistry (2018YCTUJGY006) and the innovation and entrepreneurship training program for college students in jiangsu province (201910324016Z)

\section{Abstract}

Nessler's reagent spectrophotometry is the traditional method for ammonia nitrogen $\left(\mathrm{NH}_{3}-\mathrm{N}\right)$ determination, which is adopted in the national standard of the People's Republic of China (HJ 535-2009). In order to improve the accuracy of such method, possible influences, Nessler's Reagent preparation, $\mathrm{pH}$ value of the solution, metal ions, organic solvents and natural organic matters, on $\mathrm{NH}_{3}-\mathrm{N}$ determination were discussed. The results suggested that the method $\mathrm{B}$, employing $\mathrm{KI}, \mathrm{HgI}_{2}$ and $\mathrm{NaOH}$, is preferred in Nessler's Reagent preparation. And the Nessler's Reagent Spectrophotometry may be executed over a wide $\mathrm{pH}$ range (4-11). The metal ions, organic solvents and natural organic matters have significant influences in $\mathrm{NH}_{3}-\mathrm{N}$ detection.

Keywords Nessler's Reagent, Ammonia Nitrogen, pH, Metal Ion, Organic Solvent, Natural Organic Matter.

DOI: $10.7176 / J N S R / 11-24-02$

Publication date: December $31^{\text {st }} 2020$

\section{Introduction}

The concept, ammonia-nitrogen $\left(\mathrm{NH}_{3}-\mathrm{N}\right)$ is aquatic nitrogen in form of $\mathrm{NH}_{3}$ or $\mathrm{NH}_{4}^{+}$. The main resources of $\mathrm{NH}_{3}-$ $\mathrm{N}$ are nitrogen-containing compounds from domestic wastewater, industrial wastewater and agricultural effluent. Thus, $\mathrm{NH}_{3}-\mathrm{N}$ becomes a typical indicator in (waste)water quality determination. Presently, the classical method for $\mathrm{NH}_{3}-\mathrm{N}$ determination is Nessler's reagent spectrophotometry. With the advantages of high sensitivity and easy operation, Nessler's reagent spectrophotometry is adopted in the national standard of the People's Republic of China (HJ 535-2009) ${ }^{[1]}$.

Generally, the detection limit of Nessler's reagent spectrophotometry was $0.025 \mathrm{mg} / \mathrm{L}$. Its lower limits and the upper limits are 0.10 and $2.0 \mathrm{mg} / \mathrm{L}$, respectively ${ }^{[2]}$. This method is popular in routine $\mathrm{NH}_{3}-\mathrm{N}_{\text {monitoring and in }}$ experiment course in universities. According to the quality assurance and quality control required by the national standard (HJ 535-2009), critical controls are settled on the (waste)water pre-treatment, reagent preparations and the operation procedure. However, there are still some factors may influence the $\mathrm{NH}_{3}-\mathrm{N}$ determination. Therefore, substantial investigations were given on the Nessler's reagent preparation, $\mathrm{pH}$ value of solution and coexisting interferants. The present work may provide valuable reference for national standard optimization.

\section{Principles and methods}

\subsection{Principle of ammonia nitrogen reaction}

$\mathrm{NH}_{3}-\mathrm{N}$ reacts with Nessler's reagent forming reddish-brown complexes. And the complicated reactions are outlined in equation (1)-(5). Furthermore, the $\mathrm{NH}_{3}-\mathrm{N}$ concentration is proportional to the spectrophotometric absorbance of the complex.

$$
\begin{aligned}
& 2\left[\mathrm{HgI}_{4}\right]^{2-}+\mathrm{NH}_{3}+3 \mathrm{OH}^{-} \rightarrow \mathrm{OHgHgNH}_{2} \mathrm{I} \uparrow+7 \mathrm{I}^{-}+2 \mathrm{H}_{2} \mathrm{O} \text { (Brown orange) } \\
& 2\left[\mathrm{HgI}_{4}\right]^{2-}+\mathrm{NH}_{3}+2 \mathrm{OH}^{-} \rightarrow \mathrm{OHO}-\mathrm{HgI}_{-}-\mathrm{HgNH}_{2} \mathrm{I} \uparrow+6 \mathrm{I}^{-}+\mathrm{H}_{2} \mathrm{O} \text { (Dark brown) } \\
& 2\left[\mathrm{HgI}_{4}\right]^{2-}+\mathrm{NH}_{3}+\mathrm{OH}^{-} \rightarrow \mathrm{I}-\mathrm{HgI}-\mathrm{HgNH}_{2} \mathrm{I} \uparrow+5 \mathrm{I}^{-}+\mathrm{H}_{2} \mathrm{O}(\text { chocolate) } \\
& 2\left[\mathrm{HgI}_{4}\right]^{2-}+\mathrm{NH}_{4}^{+}+4 \mathrm{OH}^{-} \rightarrow \mathrm{OHgHgNH}_{2} \mathrm{I} \uparrow+7 \mathrm{I}^{-}+3 \mathrm{H}_{2} \mathrm{O} \text { (Brown orange) } \\
& \mathrm{NH}_{4}^{+}+\mathrm{OH}^{-} \rightarrow \mathrm{NH}_{3} \cdot \mathrm{H}_{2} \mathrm{O} \rightarrow \mathrm{NH}_{3}+\mathrm{H}_{2} \mathrm{O}
\end{aligned}
$$

\subsection{Methods}

Standard solution of $\mathrm{NH}_{3}-\mathrm{N}$ : standard solutions of $\mathrm{NH}_{3}-\mathrm{N}$ were prepared employing $\mathrm{NH}_{4} \mathrm{Cl}$ (high-grade purity), which was dried at $105^{\circ} \mathrm{C}$ more than 2 hours before use.

Unless stated, all solutions were freshly prepared using ultrapure water $\left(18.2 \mathrm{~m} \Omega \cdot \mathrm{cm}^{-1}\right.$, Millipore Corp., USA). The soluble interferants were added into the standard solution of $\mathrm{NH}_{3}-\mathrm{N}$, directly. In addition, the insoluble interferants were soaked in $5 \mathrm{~mol} \cdot \mathrm{L}^{-1} \mathrm{NaOH}$ solution for 24 hour, and the filtrate was added into the standard solution of $\mathrm{NH}_{3}-\mathrm{N}$.

After the water sample was treated, $20 \mathrm{~mL}$ was put into the $50 \mathrm{~mL}$ colorimetric tube, $1.0 \mathrm{~mL}$ potassium and sodium tartrate solution, and $1.5 \mathrm{~mL}$ Nessler's reagent were added, sequentially. Then ultrapure water was added 
into the colorimetric tube to dilute the mixture to the scale mark and the colorimetric determination was conducted at the wavelength of $420 \mathrm{~nm}$.

\section{Results and discussion}

\subsection{The influence from the methods of Nessler's reagent preparation}

Given by the national standard, $\mathrm{KI}, \mathrm{HgCl}_{2}$ and $\mathrm{KOH}$ (Method $\mathrm{A}$ ), and $\mathrm{KI}, \mathrm{HgI}_{2}$ and $\mathrm{NaOH}$ (Method $\mathrm{B}$ ), are employed in Nessler's reagent preparation. $\left[\mathrm{HgI}_{4}\right]_{2}$, the critical chromophore group in the spectrophotometry can be derived in both methods. According to experimental results, the blank value obtained in Method A is 0.025 , while that is 0.029 in Method B. Both of them are within the scope acquired by the national standard. Additionally, during the calibration employing two type of Nessler's reagents, the correlation coefficients are 0.9986 (Method A) and 0.9990 (Method B), respectively.

Considering the preparation of Nessler's reagent, Method B is preferred based on the results above. Firstly, in Method A, it takes a lot of time to prepare saturated $\mathrm{HgCl}_{2}$ solution, because of the slow dissolution of $\mathrm{HgCl}_{2}$ in KI solution. Secondly, the impurities of $\mathrm{KOH}$ in Method A produce some sediment, which cause long-time precipitation process and complicated preparation. Thirdly, Nessler's reagent prepared in Method B has longer shelf life about 1 year, which minimizes the $\mathrm{Hg}$-containing reagent waste.
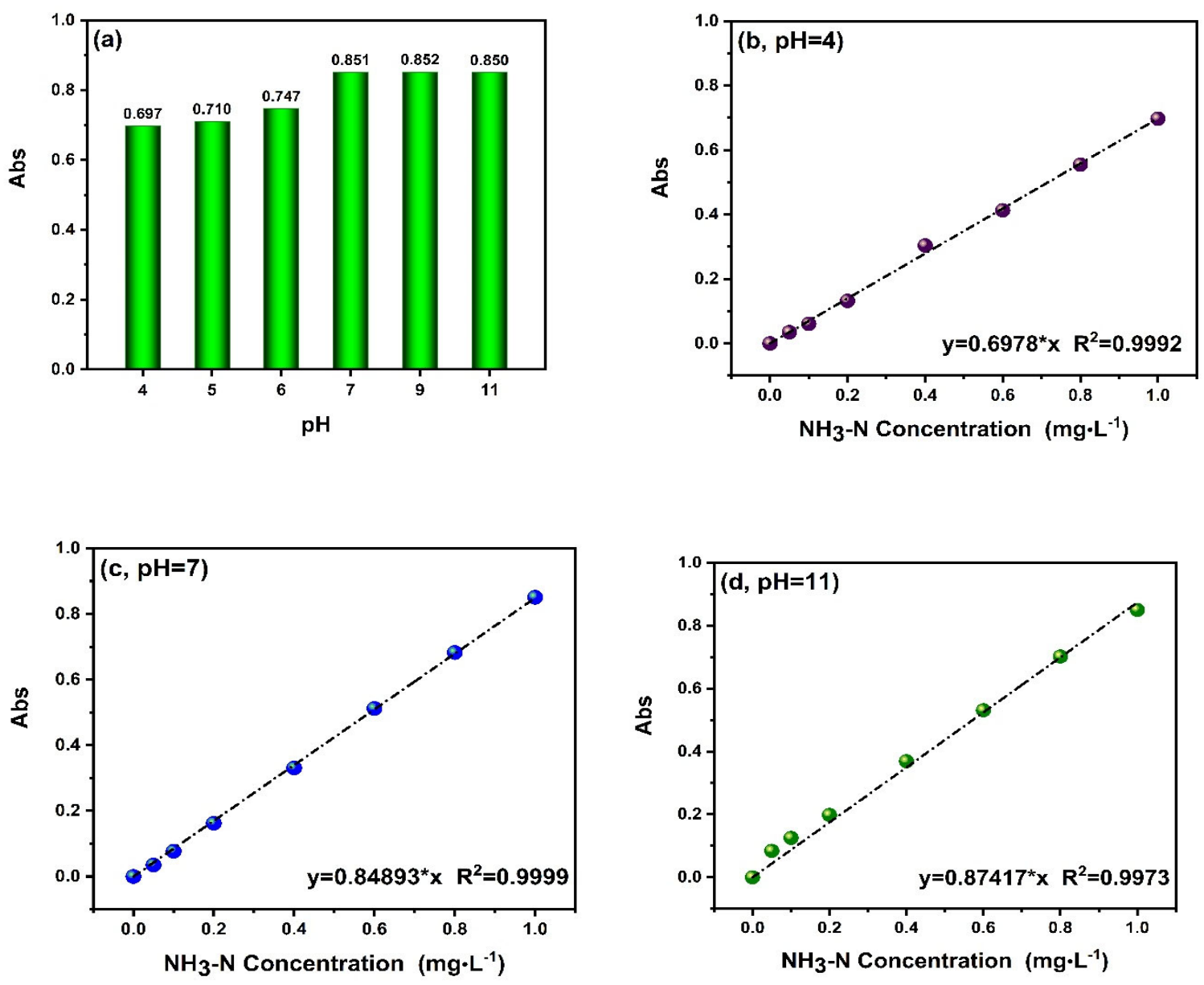

Figure 1. The influence from $\mathrm{pH}$ on $\mathrm{NH} 3-\mathrm{N}$ detection.

\subsection{The influence from $\mathrm{pH}$ on $\mathrm{NH}_{3}-\mathrm{N}$ detection}

Solution $\mathrm{pH}$ is investigated for its possible impacts on $\mathrm{NH}_{3}-\mathrm{N}$ detection ${ }^{[3]}$. The $\mathrm{NH}_{3}-\mathrm{N}$ solutions $\left(1 \mathrm{mg} \cdot \mathrm{L}^{-1}\right)$ with desired $\mathrm{pH}$ were adjusted by $\mathrm{H}_{2} \mathrm{SO}_{4}\left(0.5 \mathrm{~mol} \cdot \mathrm{L}^{-1}\right)$ or $\mathrm{NaOH}\left(1 \mathrm{~mol} \cdot \mathrm{L}^{-1}\right)$ solution. As shown in Figure 1a, the absorbance in the spectrophotometry (Abs) increases with raised $\mathrm{pH}$ value $(\mathrm{pH}<7)$, while the Abs is insensitive to $\mathrm{pH}$ value in the range of 7-11. As depicted in Figure $1 \mathrm{~b}-\mathrm{d}$, the Abs is in good correlation with $\mathrm{NH}_{3}-\mathrm{N}_{\text {concentration }}$ over acidic, neutral and alkaline conditions.

\subsection{The influence from metal ions}

The effect of certain metal ions, $\mathrm{Mn}^{2+}, \mathrm{Zn}^{2+}, \mathrm{Cd}^{2+}, \mathrm{Co}^{2+}, \mathrm{Cu}^{2+}, \mathrm{Ni}^{2+}$ and $\mathrm{Pb}^{2+}$, on the $\mathrm{NH}_{3}-\mathrm{N}$ detection was 
investigated. The $\mathrm{NH}_{3}-\mathrm{N}$ solutions $\left(1 \mathrm{mg} \cdot \mathrm{L}^{-1}\right)$ with certain metal ion $\left(5 \mathrm{mmol} \cdot \mathrm{L}^{-1}\right)$ component were prepared at $\mathrm{pH}$ 4. To exclude the interference stems from the color of ions, special reference was prepared with corresponding metal ion, but without $\mathrm{NH}_{3}-\mathrm{N}$ and Nessler's reagent. The results presented in Figure 2 shows the influence varies with metal ions. Specifically, $\mathrm{Mn}^{2+}$ has imperceptible interference, $\mathrm{Zn}^{2+}, \mathrm{Cd}^{2+}$ and $\mathrm{Co}^{2+}$ have weak interference, however $\mathrm{Cu}^{2+}, \mathrm{Ni}^{2+}$ and $\mathrm{Pb}^{2+}$ exerts obvious interference. For example, $\mathrm{Pb}^{2+}$ caused $\mathrm{Abs}$ increase about $13 \%$. Considering the $\lg \beta \mathrm{n}$ between corresponding metal ions and ligand (Table 1), $\mathrm{Zn}^{2+}, \mathrm{Cd}^{2+}, \mathrm{Co}^{2+}, \mathrm{Cu}^{2+}, \mathrm{Ni}^{2+}$ and $\mathrm{Pb}^{2+}$, especially for $\mathrm{Cu}^{2+}, \mathrm{Ni}^{2+}$ and $\mathrm{Pb}^{2+}$, have intensive complexation tendency towards $\mathrm{NH}_{3}$. Thus, it is hard for potassium sodium tartrate with a final concentration about $40 \mathrm{mmol} \cdot \mathrm{L}^{-1}$ to mask the interference from such metal ions totally.

\subsection{The influence from organic solvents}

Organic solvents, such as methanol (MT), dimethyl formamide (DMF), dimethyl sulfoxide (DMSO), ethanol (ET), acetonitrile $(\mathrm{ACN})$, acetone $(\mathrm{CP})$ and trimethylamine (TEA), are extensively used in manufacturing process. These organic solvents coexist with $\mathrm{NH}_{3}-\mathrm{N}$ in the (waste)water samples ${ }^{[4]}$. Therefore, it was of great significance to evaluate the influences from such organic solvents on $\mathrm{NH}_{3}-\mathrm{N}$ detection employing the Nessler's reagent spectrophotometry. Accordingly, the $\mathrm{NH}_{3}-\mathrm{N}$ solutions $\left(1 \mathrm{mg} \cdot \mathrm{L}^{-1}\right)$ with certain organic solvent $\left(5 \mathrm{mmol} \cdot \mathrm{L}^{-1}\right)$ were prepared at $\mathrm{pH} 7$. As shown in Figure 3, the organic solvents cause non-determinacy in $\mathrm{NH}_{3}-\mathrm{N}$ detection. Furthermore, the interference depends on the type of the organic compounds. The impact from methanol (MT), dimethyl formamide (DMF), acetone (CP) and ethanol (ET) is negligible. However, acetonitrile (ACN), dimethyl sulfoxide (DMSO) and trimethylamine (TEA) raise the $\mathrm{Abs}$ of $\mathrm{NH}_{3}-\mathrm{N}$ detection significantly. As for trimethylamine (TEA), these is an increase more than $16 \%$ observed.

Table 1 . The parameters of $\lg \beta$ n between corresponding metal ions and ligands ${ }^{[4]}$.

\begin{tabular}{cccc}
\hline Ligand & Metal ion & Number of ligand & $\mathbf{l g} \boldsymbol{\beta} \mathbf{n}$ \\
\hline & $\mathrm{Hg}^{2+}$ & 1 & 7.0 \\
& $\mathrm{Cd}^{2+}$ & 1 & 2.8 \\
& $\mathrm{Co}^{2+}$ & 1 & 2.1 \\
potassium sodium tartrate & $\mathrm{Cu}^{2+}$ & $1,2,3,4$ & $3.2,5.11,4.78,6.51$ \\
& $\mathrm{Mn}^{2+}$ & 1 & 2.49 \\
& $\mathrm{Ni}^{2+}$ & 1 & 2.06 \\
& $\mathrm{~Pb}^{2+}$ & 1,3 & $3.78,4.7$ \\
& $\mathrm{Zn}^{2+}$ & 1,2 & $2.68,8.32$ \\
& $\mathrm{Hg}^{2+}$ & $1,2,3,4$ & $8.8,17.5,18.5,19.28$ \\
& $\mathrm{Cd}^{2+}$ & $1,2,3,4,5,6$ & $2.65,4.75,6.19,7.12,6.80,5.14$ \\
& $\mathrm{Co}^{2+}$ & $1,2,3,4,5,6$ & $2.11,3.74,4.79,5.55,5.73,5.11$ \\
& $\mathrm{Cu}^{2+}$ & $1,2,3,4,5$ & $4.31,7.98,11.02,13.32,12.86$ \\
$\mathrm{NH}_{3}$ & 1,2 & $0.8,1.3$ \\
& $\mathrm{Mn}^{2+}$ & $1,2,3,4,5,6$ & $2.80,5.04,6.77,7.96,8.71,8.74$ \\
& $\mathrm{Ni}^{2+}$ & $1,2,3,4$ & $9.6,18.5,26.0,32.8$ \\
& $\mathrm{~Pb}^{2+}$ & $1,2,3,4$ & $2.37,4.81,7.31,9.46$ \\
\hline
\end{tabular}



Figure 2. The influence from metal ions on $\mathrm{NH}_{3}-\mathrm{N}$ detection. 




Figure 3. The influence from organic solvents on $\mathrm{NH}_{3}-\mathrm{N}$ detection.

\subsection{The influence from natural organic matters}

Natural organic matter (NOM) is a series of complicated organic materials and a ubiquitous component in (waste)water samples ${ }^{[3]}$. Interactions between the hydrologic cycle and the biosphere and geosphere shape the amount, character and properties of NOM in the environments. In this study, to evaluate the influence from NOM, the sediments (20 g) from marine (MS), river (RS), lake (LS) and swamp (SS) were soaked in $5 \mathrm{~mol} \cdot \mathrm{L}^{-1} \mathrm{NaOH}$ solution $(50 \mathrm{~mL})$ for 24 hour, and the filtrates $(20 \mathrm{~mL})$ were added into the standard solutions of $\mathrm{NH}_{3}-\mathrm{N}$, using humic acid (HA) and fulvic acid (FA) as the references. Additionally, the $\mathrm{NH}_{3}-\mathrm{N}$ solutions $\left(1 \mathrm{mg} \cdot \mathrm{L}^{-1}\right)$ with certain $\mathrm{NOM}$ were prepared at $\mathrm{pH}$ 11. As presented in Figure 4, the NOMs have significant influence on $\mathrm{NH}_{3}-\mathrm{N}$ detection. The leaching solutions from the various sediments reinforce the Abs in the spectrophotometry, resembling the influences of humic acid (HA) and fulvic acid (FA). The results indicate that the sediments may reinforce the Abs in the Nessler's Reagent Spectrophotometry, by releasing the NOMs, such as humic acid and fulvic acid.

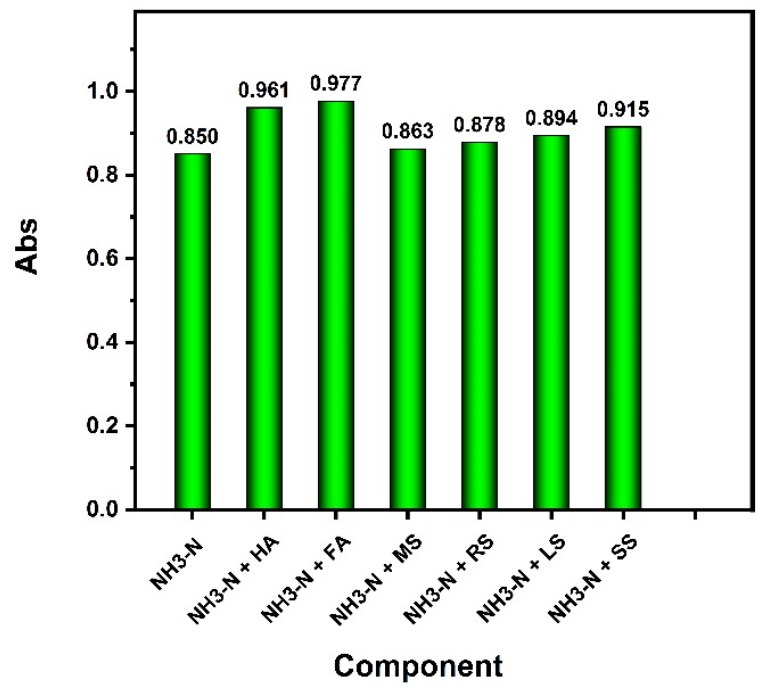

Figure 4. The influence from natural organic matters on $\mathrm{NH}_{3}-\mathrm{N}$ detection.

\section{Conclusion}

In summary, the influences from the Nessler's Reagent preparation, $\mathrm{pH}$ value of the solution, metal ions, organic solvents and natural organic matters were investigated. The results indicated that the method $\mathrm{B}\left(\mathrm{KI}, \mathrm{HgI}_{2}\right.$ and $\mathrm{NaOH}$ ) is preferred in Nessler's Reagent preparation. The Nessler's Reagent Spectrophotometry may be executed over a wide $\mathrm{pH}$ range (4-11). The metal ions, organic solvents and natural organic matters have significant influences in $\mathrm{NH}_{3}-\mathrm{N}$ detection, which need to be eliminated.

\section{References}

[1]Editorial committee of water and waste water monitoring and analysis methods, state environmental protection bureau. Water and waste water monitoring and analysis methods. 3rd edition. Beijing: China environmental science press, 1989.255. 
[2]Guide to monitoring and analysis methods for water and wastewater, editorial board. Guide to monitoring and analysis methods for water and wastewater. Beijing: China environmental science press, 1989.140.

[3]Zhao Yunxuan, Shi Run, Bian Xuanang, Zhou Chao, Zhao Yufei, Zhang Shuai, Wu Fan, Waterhouse Geoffrey I. N., Wu Li-Zhu, Tung Chen-Ho and Zhang Tierui. Ammonia Detection Methods in Photocatalytic and Electrocatalytic Experiments: How to Improve the Reliability of $\mathrm{NH}_{3}$ Production Rates? Advanced Science, 2019.

[4]Shui Yonghong, Shui Aishe, Li Jian, Wei Yujun, Duan Xiaolang, Jiang Xuejun and Zheng Xiong. Ammonia Nitrogen Determination and Application in Constructed Wetland. 2013 International Conference on Frontiers of Environment, Energy and Bioscience (ICFEEB 2013).

[4]Wu He-Zhen and Cao Aie. Preparation and Adding Methods of Nessler's Reagent Having Effects on Determination of Water Quality Ammonia Nitrogen. Advanced Materials Research, 2013. 